\title{
Optimization of inulin production process parameters using response surface methodology
}

\author{
Wasim Akram* and Navneet Garud
}

\begin{abstract}
Background: Chicory is one of the major source of inulin. In our study, Box-Behnken model/response surface analysis (RSM) was used for the optimization of spray drying process variables to get the maximum inulin yield from chicory (Cichorium intybus L.). For this investigation, the investigational plan utilized three process variables drying temperature $\left(115-125^{\circ} \mathrm{C}\right)$, creep speed $(20-24 \mathrm{rpm})$, and pressure $(0.02-0.04 \mathrm{MPa})$.

Result: The optimal variables established by applying the Box-Behnken model were as follows: drying temperature $119.20^{\circ} \mathrm{C}$, creep speed $21.64 \mathrm{rpm}$, and pressure $0.03 \mathrm{MPa}$. The obtained powdered inulin by spray drying was investigated for the yield value, identification, size, and surface morphology of the particle. The inulin obtained from the spray drying process consists of a fine molecule-sized white powder. Instead, the drying methods shows a significant effect on the morphology and internal configuration of the powdered inulin, as the inulin obtained from spray drying was of a widespread and uniform size and shape, with a rough surface on increase in temperature and smoother surface while increasing the creep speed. The findings indicate that the spray drying with optimum parameters resulted in maximum product yield.

Conclusion: The outcomes of the study concluded that the product yield through spray drying technique under optimized condition is optimal as compared to other drying technique. Hence, this technique may be applied at commercial scale for the production of inulin.
\end{abstract}

Keywords: Inulin, Spray drying process, Optimization, Box-Behnken design/response surface methodology

\section{Background}

The chicory, tuberous roots that store inulin, may be a native plant from Europe, Asia, Africa, and South America, but it often cultivates altogether over the planet [1]. Chicory (Cichorium intybus L.) may be a biennial plant which comes under the Asteraceae family with many applications within the food industry. The roots of chicory are the principal source of inulin [2]. Inulin could be a fructan which generally composed of 1, 2-[3-1inked D-fructofuranose entities bound by an (od-132) type bond to a terminal glucose moiety. By taxation, inulin primarily made up of linear fructose segments knotted via a $\beta-(2-6)$ glycosidic

* Correspondence: wasimjiwaji@gmail.com

School of Studies in Pharmaceutical Sciences, Jiwaji University, Gwalior, Madhya Pradesh, India

Springer Open bond [3]. Inside the human, inulin may act in parallel with dietary fibers, adding to the general improvement in the gastrointestinal state. Due to these belongings, the food and pharmaceutical sector utilizes inulin for the manufacture of functional foods, nutritional products, in drug delivery system and medications; it may function as a prebiotic which stimulates the growth of the number of useful microorganisms, specifically bifidobacteria which can improve host health and diminishes mucosal inflammation in the colon $[4,5]$.

The number of the monomeric unit and relative molar mass of inulin mainly depends on the plant used for the isolation. The degree of inulin polymerization (DP) varies between 2 and 70, with inulin having the degree of polymerization less than 10 recognized as oligofructose or

(c) The Author(s). 2020 Open Access This article is licensed under a Creative Commons Attribution 4.0 International License, which permits use, sharing, adaptation, distribution and reproduction in any medium or format, as long as you give appropriate credit to the original author(s) and the source, provide a link to the Creative Commons licence, and indicate if changes were made. The images or other third party material in this article are included in the article's Creative Commons licence, unless indicated otherwise in a credit line to the material. If material is not included in the article's Creative Commons licence and your intended use is not permitted by statutory regulation or exceeds the permitted use, you will need to obtain permission directly from the copyright holder. To view a copy of this licence, visit http://creativecommons.org/licenses/by/4.0/. 
shorter-chain inulin, and inulin having a degree of polymerization greater than 23 known as polyfructose or longer-chain inulin [6, 7]. Furthermore, inulin as an indigestible carbohydrate can also be utilized as a fat alternative for foodstuffs.

Inulin is generally traded as a powder for easy to pickup, shipping, and storage [8]. The production technique used to get dried powder inulin is enormously important in defining its grade. At present, freeze drying and spray drying are commonly used techniques for powdered inulin production [9]. The technique lyophilization/freeze drying embraces evaporation and elution and normally needed 2 or 2.5 days for acquiring a spongy and loose product [10]. The freeze drying technique is in demand for packaging and depot; subsequently, the dry powder grips moistness and may be simply oxidated when unveiling to the environment [11, 12]. Additionally, it is a technique with the high cost and thin productivity. Consequently, spray drying was generally used drying technique within the food sector because it is inexpensive and has great pliability [13].

The spray drying technique utilizes a vaporizer to diffuse the fluid into small globules and quickly vaporizes the solution in the dried environment to get a product in powdered form. Ritual yield is frequently accomplished by differing factors like temperature, viscidness, input ratio, or micronizing pressure [14]. The resulting dry powder features particles of uniform size with great sphericity. For example, during a preceding study, Jerusalem artichoke pectin properties were assessed, obtained by employing different methods (vacuum drying, freezing and spray drying), and consequently, the researchers found spray drying is the best among the above used technique [15].

The main objective of our work was, therefore, to optimize the different parameters of the spray drying technique through the execution of response surface methodology/Box-Behnken model to get the maximum production of inulin.

\section{Methods}

\section{Materials}

Chicory root was obtained from a market of Gwalior, Madhya Pradesh, India. The Botanical Survey of India, Central Regional Centre, Allahabad, under the aegis of the Ministry of Environment, Forest and Climate Change, identified and authenticated the plant specimen. The authentication accession no. is 102272. The supplementary materials utilized in the current research work were of analytical rank and were secured from Hi-Media Laboratories Ltd. (Mumbai, India).

\section{Preparation of chicory extract}

The chicory roots were collected; after that, they were clean with tap water and dehydrated at $40{ }^{\circ} \mathrm{C}$ within the vacuum oven. The grounded taproots were extracted with hot water $\left(\sim 90^{\circ} \mathrm{C}\right)$ under the pressure of $1.5 \mathrm{MPa}$ for 2-3 min. Repeating the extraction twice, the filtrates were mixed and the $\mathrm{pH}$ was adjusted to 8.0 by adding $\mathrm{Ca}(\mathrm{OH})_{2}$. The blend was left at ambient temperature for $1 \mathrm{~h}$. Afterwards, the sludge was filtrated. The residues were neutralized to $\mathrm{pH} 7$ at temperature $60-65^{\circ} \mathrm{C}$ by oxalic acid. Activated carbon was added then the filtration process was done again. The residue was precipitated by addition of acetone and left to settle down at $2-5^{\circ} \mathrm{C}$. The resulting amorphous substance was filtered, washed with ethanol twice, acetone once, and finally dried at $40{ }^{\circ} \mathrm{C}$ [2] (Fig. 1).

\section{Development of inulin powder}

Inulin as the dry powder was produced by employing the spray drying technique. Box-Behnken design was employed to optimize the process variables. The level of each process variables/independent factor is low, mid, and high, and their equivalent actual values are presented in Table 1. Three independent factors utilized in the Box-Behnken design were drying temperature (115$\left.125^{\circ} \mathrm{C}\right)$, speed $(20-24 \mathrm{rpm})$, and the applied pressure $(0.02-0.04 \mathrm{MPa})$. Table 2 presents the investigational runs executed according to the Design-Expert BoxBehnken model.

The data from the investigation were examined statistically via version 11.1.0.1 of Design-Expert (Stat Ease Inc., USA). Product yield remained countered to a model of quadrate regression for response surface examination.

As presented in the equation:

$$
\begin{aligned}
\text { Yield }= & \alpha_{0}+\alpha_{1} A+\alpha_{2} B+\alpha_{3} C+\alpha_{4} A B+\alpha_{5} A C \\
& +\alpha_{6} B C+\alpha_{7} A^{2}+\alpha_{8} B^{2}+\alpha_{9} C^{2}
\end{aligned}
$$

Here, A, B, and C represent temperature, creep speed, and pressure. The $\alpha$ displays values of the analogous regression. The investigation was arbitrary in taking advantage of the influence of undiscovered variation on perceived results due to extrinsic facets. Half liters of clear inulin extract was utilized with a spray-dryer (SPD-D-111) for drying experimentation; the inulin extract was propelled via a spout to the counter-current dehydrating compartment utilizing a roller pump. The extract of the product was heat-up to a defined degree before every feeding (intake temperature is greater than $60^{\circ} \mathrm{C}$, and the outlet temperature is higher than $50^{\circ} \mathrm{C}$ ). Spray drying process variables for maximum product yield were established with the help of response surface analysis assay.

\section{Characterization and analysis Determination of inulin yield}

The product yield was determined by using the following formula: 


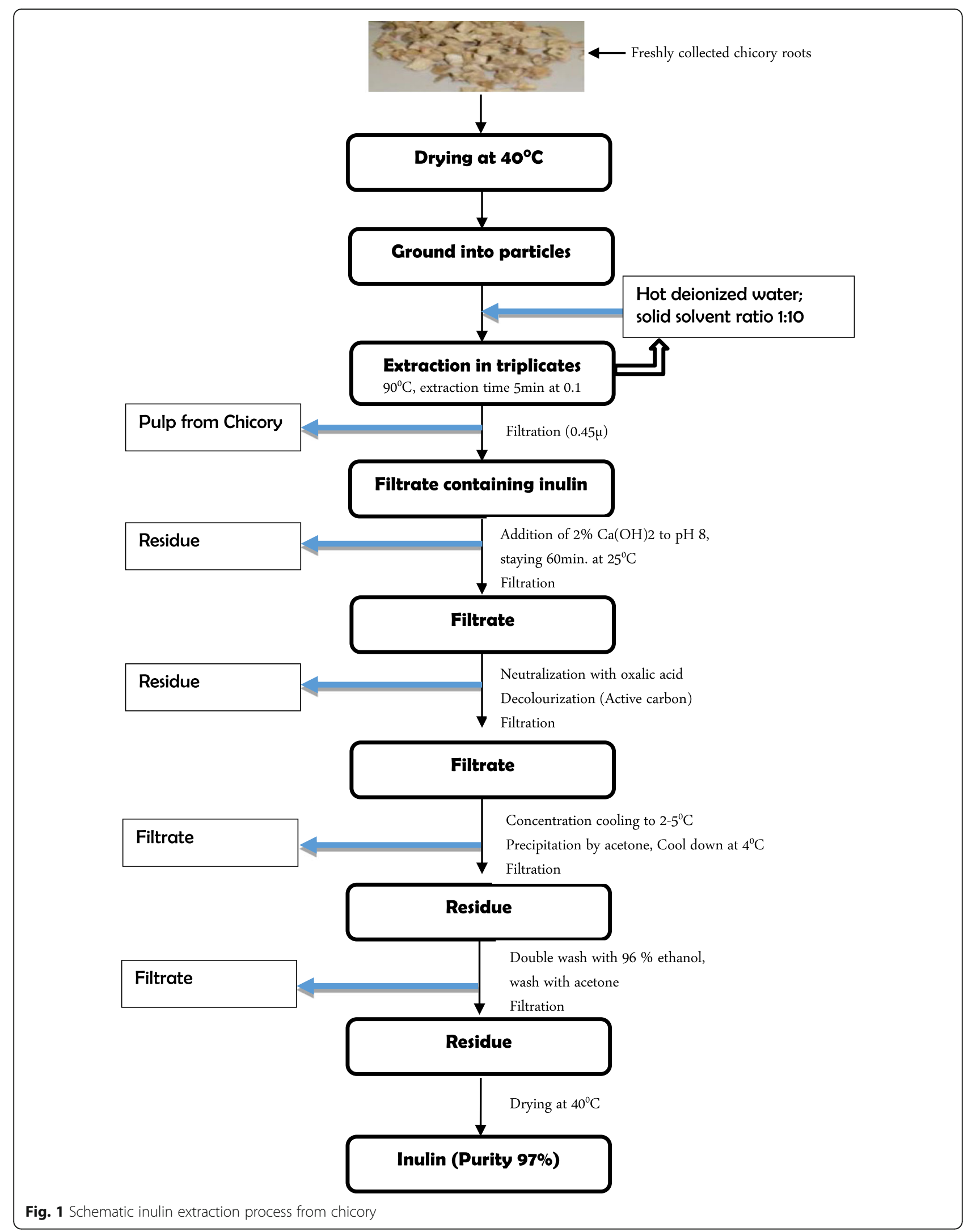


Table 1 Independent variables and levels of experimental design

\begin{tabular}{lllll}
\hline S. no. & Independent variables & \multicolumn{3}{l}{ Code level } \\
\cline { 3 - 5 } & & Low (- 1) & Mid (0) & High (+ 1) \\
\hline 1. & Heating temperature ${ }^{\circ} \mathrm{C}(\mathrm{A})$ & 115 & 120 & 125 \\
2. & Creep speed rpm (B) & 20 & 22 & 24 \\
3. & Pressure MPa (C) & 0.02 & 0.03 & 0.04 \\
\hline
\end{tabular}

$$
Y=\frac{\mathrm{mp}}{\mathrm{M}} \times 100 \%
$$

where $\mathrm{mp}(\mathrm{kg})$ is the powdered inulin mass gained from 6-L extract and $M$ is the weight of chicory root utilized in the isolation to get $6-\mathrm{L}$ extract.

\section{Identification of isolated inulin}

Fourier transform-infrared spectrometer (FT-IR) was utilized to elucidate and characterize the structure of extracted material from chicory. Inulin dry powder $(\sim 3$ $\mathrm{mg}$ ) was added with $\sim 200 \mathrm{mg}$ FTIR ranks anhydrous $\mathrm{KBr}$ and milled into a very fine powder by utilizing pestle and mortar. The disc was packed with the blend. Infrared spectrogram of a disc was taken over a wavenumber scope of $400-4000 \mathrm{~cm}^{-1}$ at a resolution of 4 $\mathrm{cm}^{-1}$ with a test speed of $1 \mathrm{~cm} / \mathrm{s}$ using the FT-IR (FT-IR 8400S, Shimadzu, Japan).

\section{Determination of melting point and degree of polymerization}

The fusion point of inulin was determined by the capillary method. A very small amount of inulin powder was inserted in a capillary tube. The capillary was inserted in the apparatus and the temperature at which inulin commenced to melt was recorded.

With the help of the following equation, the degree of polymerization of isolated chicory inulin was determined:

Degree of polymerization $=C_{\text {fructose }} / C_{\text {glucose }}+1$

where $C$ concentration, \%

\section{Study of particle size distribution and surface morphology of isolated powdered inulin}

The product's size and surface morphology was calculated using a scanning electron microscope (SEM) article JSM 5600 JEOL, Japan. The assessment of the particles size was done by assessing them on an electronic paquimeter utilizing the picture system [16]. The equivalent mean diameter of every particle was believed as the mean within two perpendicular measurements. For all investigation, the subsequent assessment was taken: mean equivalent, maximal, and minimal diameters.

\section{Results}

The extraction yield of this investigation by applying hot water extraction (conventional method) was determined as $11.96 \%$.

Table 2 Test design and results of response surface analysis (each test was performed in triplicate)

\begin{tabular}{|c|c|c|c|c|c|c|c|}
\hline \multirow[t]{2}{*}{ Run } & \multicolumn{3}{|c|}{ Coded variable } & \multicolumn{3}{|c|}{ Actual variable } & \multirow{2}{*}{$\begin{array}{l}\text { Response } \\
\text { Yield \% }\end{array}$} \\
\hline & $x$ & $Y$ & $Z$ & $A$ & $B$ & $C$ & \\
\hline 1 & 0 & +1 & -1 & 120 & 24 & 0.02 & $10.97 \pm 0.06$ \\
\hline 2 & -1 & 0 & -1 & 115 & 22 & 0.02 & $11.35 \pm 0.09$ \\
\hline 3 & +1 & -1 & 0 & 125 & 20 & 0.03 & $11.05 \pm 0.11$ \\
\hline 4 & -1 & 0 & +1 & 115 & 22 & 0.04 & $09.77 \pm 0.04$ \\
\hline 5 & 0 & +1 & +1 & 120 & 24 & 0.04 & $09.35 \pm 0.03$ \\
\hline 6 & 0 & 0 & 0 & 120 & 22 & 0.03 & $12.03 \pm 0.14$ \\
\hline 7 & 0 & 0 & 0 & 120 & 22 & 0.03 & $12.16 \pm 0.15$ \\
\hline 8 & 0 & 0 & 0 & 120 & 22 & 0.03 & $11.98 \pm 0.14$ \\
\hline 9 & +1 & 0 & -1 & 125 & 22 & 0.02 & $10.50 \pm 0.07$ \\
\hline 10 & 0 & -1 & +1 & 120 & 20 & 0.04 & $09.95 \pm 0.02$ \\
\hline 11 & +1 & 0 & +1 & 125 & 22 & 0.04 & $09.55 \pm 0.05$ \\
\hline 12 & +1 & +1 & 0 & 125 & 24 & 0.03 & $10.33 \pm 0.07$ \\
\hline 13 & -1 & -1 & 0 & 115 & 20 & 0.03 & $10.20 \pm 0.06$ \\
\hline 14 & -1 & +1 & 0 & 115 & 24 & 0.03 & $10.66 \pm 0.07$ \\
\hline 15 & 0 & -1 & -1 & 120 & 20 & 0.02 & $10.48 \pm 0.08$ \\
\hline 16 & 0 & 0 & 0 & 120 & 22 & 0.03 & $12.16 \pm 0.18$ \\
\hline 17 & 0 & 0 & 0 & 120 & 22 & 0.03 & $12.98 \pm 0.22$ \\
\hline
\end{tabular}

$\mathrm{X} \& \mathrm{~A}, \mathrm{Y} \& \mathrm{~B}, \mathrm{Z} \& \mathrm{C}$ indicate the temperature $\left({ }^{\circ} \mathrm{C}\right)$ creep speed and applied pressure respectively 
Optimization of spray drying technique with the help of response surface analysis

Table 2 presents the experimental plan for the spray drying process and consequently the results obtained by using Box-Behnken design to optimize inulin isolation. Likewise, the analysis of variance (ANOVA) investigation is shown in Table 3.

12.97 model $F$ value indicates the model is significant. $p$ values under 0.050 specify system levels are significant. Our study shows $C, A^{2}, B^{2}$, and $C^{2}$ are significant levels. $p$ values higher than 0.100 specify the levels are insignificant. $0.67 F$ value of lack of fit implies that in relation to the pure error, the lack of fit is insignificant and the insignificant lack of fit is best.

Table 2 investigation findings are fitted with regression, and the final equation for securing the coded variables through statistics scanning is presented in Eq. (1). The true variable regression is set out in Eq. (2).

$$
\begin{aligned}
Y= & 12.26-0.0687 \times X-0.0462 \times Y-0.5850 \\
& \times Z-0.2950 \times X Y+0.1575 \\
& \times X Z-0.2725 \times Y Z-0.7985 \\
& \times X^{2}-0.9035 \times Y^{2}-1.17 Z^{2} \\
Y= & -639.15525+8.20635 \times A+13.86412 \\
& \times B+565.85000 \times C-0.029500 \times A B \\
& +3.15000 \times A C-13.62500 B C-0.031940 \\
& \times A 2-0.225875 \times B 2-11710.00000 \times C 2
\end{aligned}
$$

The comprehensive $p$ value of the model is 0.0014 which is less than 0.01 , indicating regression equation is significant, and $p$ value for lack of fit is 0.6132 which is greater than 0.05 , representing insignificant lack of fit. It represents equation fitting is comparatively acceptable. Regression study (Table 3) revealed $A^{2}, B^{2}$, and $C^{2}$ show a noteworthy impact on product yield. Likewise, the influence of the variables on yield showing significance as per the order: drying temperature < creep speed < applied pressure.

Figure 2 presents the clear vision of the contour plot, the outline of the $3 \mathrm{D}$ response surface, and distinctly presenting the influence of the collaboration of the independent variables on the yield value. Figure $2 a-c$ presents the consequences of independent variables on the response. When the heating temperature goes $110{ }^{\circ} \mathrm{C}$ to $120^{\circ} \mathrm{C}$, the value of yield initially increases and afterwards decreases. This fact is often accredited an improved drying technique when the heating temperature was elevated, though it may cause decay of inulin moiety. Also, the rise in creep speed and applied pressure shows an equivalent drift concerning variation in product yield.

\section{Identification of isolated inulin}

The isolated inulin sample FT-IR was interpreted and checked with the standard IR spectrum shown in Fig. 3. Full information on the FT-IR spectra of chicory-isolated inulin was shown in Table 4. The peaks at $1131 \mathrm{~cm}^{-1}, 1087 \mathrm{~cm}^{-1}$, and $1031 \mathrm{~cm}^{-1}$ are representative for $(C-C, C-O, C-O-C)$ stretching bands in the fructo-furanose ring. 2-keto in fructofuranose contains band at $874 \mathrm{~cm}^{-1}$ and $821 \mathrm{~cm}^{-1}$, which are signals for existence of $\beta-(2 \rightarrow 1)$ glycosidic bonds. Our investigation is very much similar to the reported bands for inulin by Grube and Olennikov [17, 18].

Table 3 ANOVA for quadratic model. Response 1: yield

\begin{tabular}{lllllll}
\hline Basis & Sum of squares & Degree of freedom & Mean square & $\boldsymbol{F}$ value & $\boldsymbol{p}$ value & Significance \\
\hline Quadratic model & 16.78 & 9 & 1.86 & 12.97 & 0.0014 & Significant \\
A-Temperature & 0.0378 & 1 & 0.0378 & 0.2630 & 0.6239 \\
B-Creep speed & 0.0171 & 1 & 0.0171 & 0.1190 & 0.7402 \\
C-Pressure & 2.74 & 1 & 2.74 & 19.04 & 0.0033 \\
AB & 0.3481 & 1 & 0.3481 & 2.42 & 0.1637 \\
AC & 0.0992 & 1 & 0.0992 & 0.6901 & 0.4336 \\
BC & 0.2970 & 1 & 0.2970 & 2.07 & 0.1938 \\
A $^{2}$ & 2.68 & 1 & 2.68 & 18.67 & 0.0035 \\
B $^{2}$ & 3.44 & 1 & 3.44 & 23.90 & 0.0018 \\
C $^{2}$ & 5.77 & 1 & 5.77 & 40.15 & 0.0004 \\
Residual & 1.01 & 7 & 0.1438 & & 0.6132 \\
Lack of fit & 0.3369 & 3 & 0.1123 & 0.6707 & Not significant \\
Pure error & 0.6697 & 4 & 0.1674 & & \\
Cor total & 17.79 & 16 & & &
\end{tabular}

$A, B$, and $C$ are the temperature, creep speed, and pressure respectively 


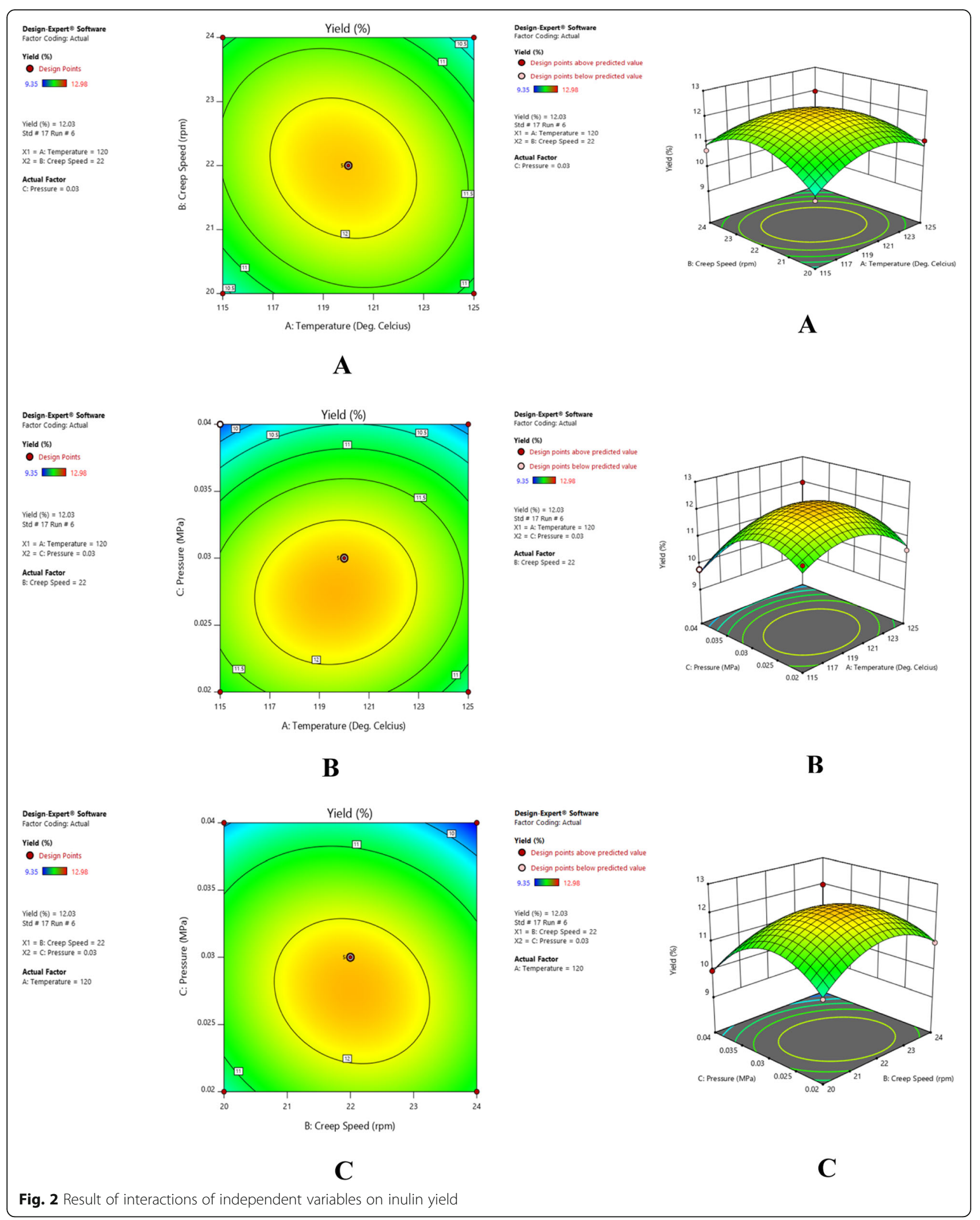




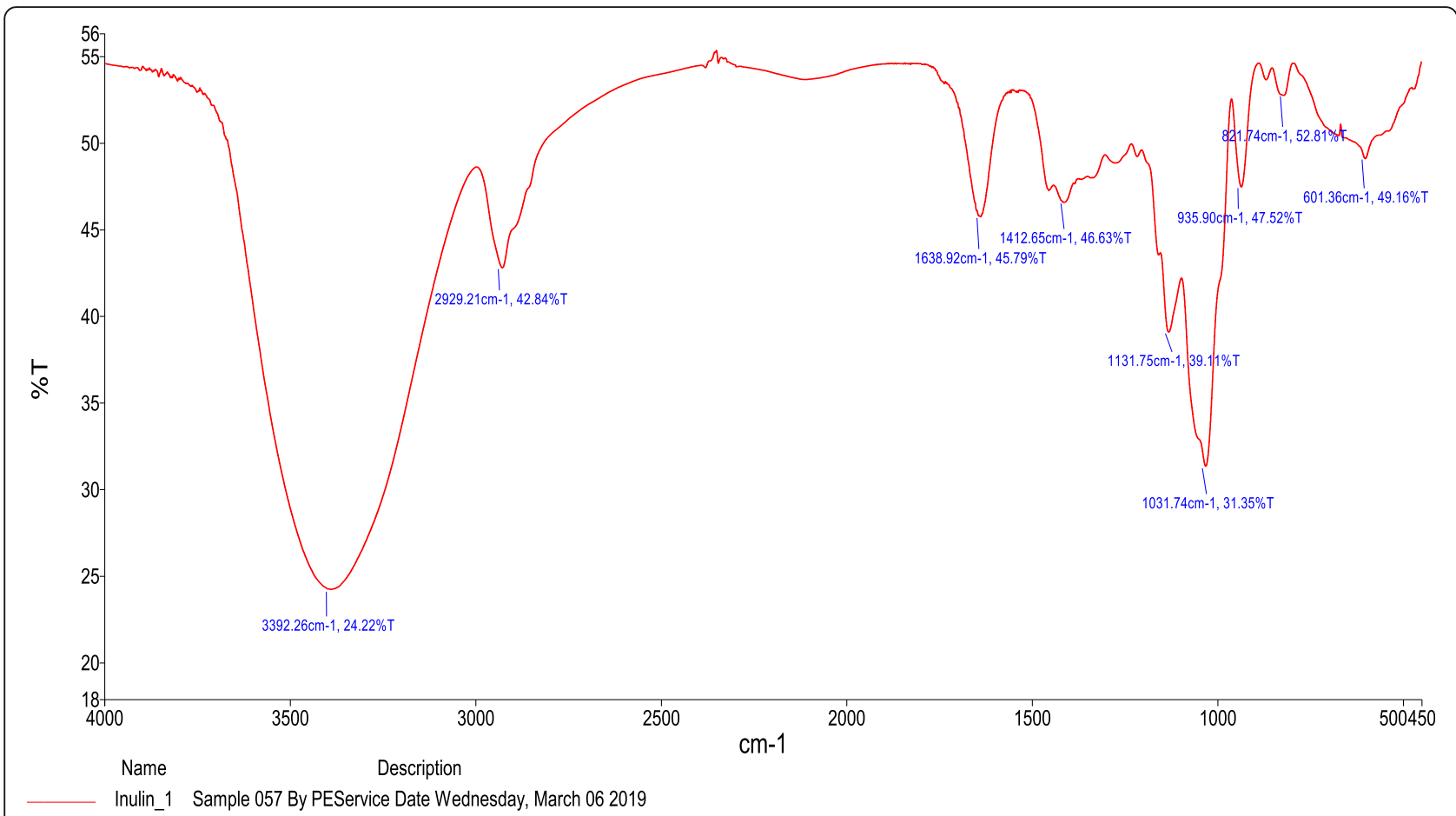

Fig. 3 FT-IR spectra of inulin isolated from chicory root

\section{Determination of melting point and degree of polymerization} The fusion point of isolated powdered inulin was found in the range of $163-164{ }^{\circ} \mathrm{C}$ which was very close to the standard reported by Nadezhda and Panteley [2]. The determined degree of polymerization of extracted inulin was 26 . This value is nearby to the degree of polymerization 23 stated by Praznik and Beck for inulin obtained from chicory roots [19].

Table 4 Interpretation of FT- IR spectra of isolated inulin

\begin{tabular}{|c|c|c|}
\hline Wave number $\mathrm{cm}^{-1}$ & IR bands $\mathrm{cm}^{-1}$ & Interpretation \\
\hline $3200-3400$ & 3361 & $\begin{array}{l}\mathrm{V}_{\mathrm{O}-\mathrm{H}}(\mathrm{OH}) \text {; intermolecular } \\
\mathrm{H} \text {-bonds }\end{array}$ \\
\hline 2933-2981 & 2931 & $V_{C-H}{ }^{\text {as }}(\mathrm{CH} 2)$ \\
\hline 2850-2904 & 2880 & $V_{C-H^{5}}\left(C_{2}\right)$ \\
\hline 1664-1634 & 1635 & Absorption of water \\
\hline $1416-1430$ & 1430 & $\delta_{C-H^{5}}\left(\mathrm{CH}_{2}\right)$ \\
\hline $1335-1336$ & 1336 & $\beta_{\mathrm{O}-\mathrm{H}}(\mathrm{OH})$ \\
\hline $1225-1235$ & 1220 & $\beta_{\mathrm{O}-\mathrm{H}}(\mathrm{OH})$ \\
\hline 1125-1162 & 1135 & $\mathrm{~V}_{\mathrm{C}-\mathrm{O}-\mathrm{C}^{\text {as }}}(\mathrm{C}-\mathrm{O}-\mathrm{C})$ \\
\hline 1015-1060 & 1031 & $\begin{array}{l}\mathrm{V}_{\mathrm{C}-\mathrm{O}}(\mathrm{C}-\mathrm{O}) \\
\mathrm{C}-\mathrm{O}\end{array}$ \\
\hline 985-996 & 987 & $v_{C-O}(C-O)$ \\
\hline 930 & 935 & a-D-Glcp residue in chain \\
\hline $\begin{array}{l}892-895 \\
874\end{array}$ & $\begin{array}{l}873 \\
873\end{array}$ & $\begin{array}{l}\text { Anomeric bendings } \delta(\mathrm{C} 1-\mathrm{H}) \text {, } \\
\text { ring vibration ( } 2 \text {-ketofuranose) }\end{array}$ \\
\hline 818 & 820 & 2-ketose \\
\hline
\end{tabular}

\section{Study of particle size distribution and surface} morphology of isolated powdered inulin

SEM pictures showing powder product samples obtained from trials clearly illustrate that the high pace of the siphon shows irregular surfaces of the inulin particles. In the same way, the SEM image displays the high temperature result in particles with the smoother surface as depicted in Fig. 4a (run 1) and b (run 3). The mean diameter of all drying situations, as well as extents of maxima and minima of the diameters, is presented in Table 5.

\section{Discussion}

The method for isolation of inulin from chicory roots was simple to execute. The isolated inulin was characterized as an odorless and tasteless cremish-white powder with melting point $163-164{ }^{\circ} \mathrm{C}$ which was very close to the reported melting point by Nadezheda and Panteley [2]. The determined degree of polymerization of isolated product was 26. This value is nearby to the degree of polymerization 23 stated by Praznik and Beck for inulin obtained from chicory roots [19] and 25 for highperformance inulin extracted from chicory witloof [20]. The FT-IR spectrum of isolated inulin show very much similar to the reported bands for inulin by Grube and Olennikov [17, 18]. The result findings from IR spectrum demonstrate that the isolated material from roots of chicory is inulin-type fructan. 


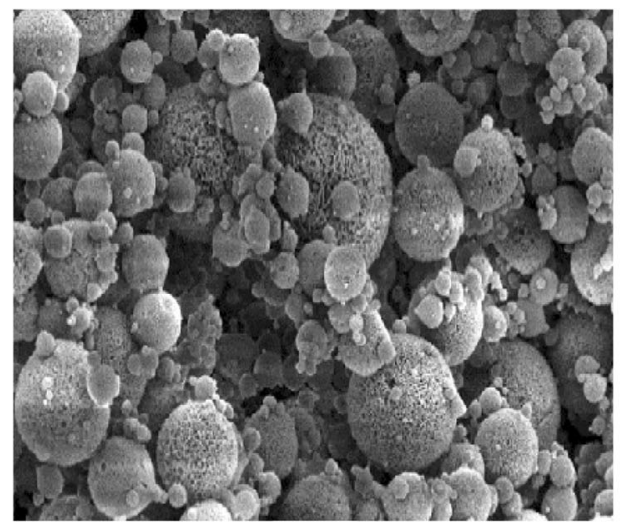

A

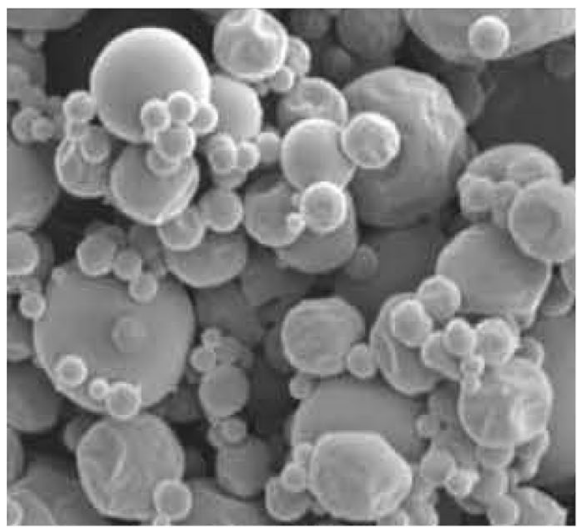

B

Fig. 4 SEM images of inulin powder. a Run 1 presenting the rough surface and $\mathbf{b}$ run 3 presenting the smooth surface of the particles

As per the investigational statistics and design study, the maximum product yield might be accomplished under the ideal conditions: drying temperature of $119.20^{\circ} \mathrm{C}$, the creeping speed of $21.64 \mathrm{rpm}$, and the applied pressure of $0.03 \mathrm{MPa}$, resulting in a product yield of $11.96 \%$. To check the accessibility and accuracy of the regression study acquired within the Box-Behnken model for the response surface analysis, the above said ideal process variables were utilized for the confirmation trial. For the process accessibility, the drying temperature was fixed at $120^{\circ} \mathrm{C}$, the creeping speed was $22 \mathrm{rpm}$, the applied pressure was 0.03 $\mathrm{MPa}$, and 3 analyses were executed in similar. In these confirmation trials, the product yield was $12.02 \pm 0.52 \%$,

Table 5 Inulin powder average equivalent diameter and maximal and minimal diameters obtained at different Runs

\begin{tabular}{llll}
\hline Run & Diameter $_{\text {Avg }}(\mathrm{nm})$ & Diameter $_{\text {max }}(\mathrm{nm})$ & Diameter $_{\min }(\mathrm{nm})$ \\
\hline 1 & $345.8 \pm 32$ & $766.5 \pm 42$ & $42.5 \pm 0.5$ \\
2 & $452.6 \pm 22$ & $725.6 \pm 54$ & $38.3 \pm 0.5$ \\
3 & $458.5 \pm 30$ & $765.2 \pm 60$ & $35.6 \pm 0.8$ \\
4 & $366.2 \pm 26$ & $802.8 \pm 75$ & $40.2 \pm 1.0$ \\
5 & $389.4 \pm 18$ & $785.6 \pm 66$ & $33.5 \pm 0.7$ \\
6 & $335.8 \pm 25$ & $792.5 \pm 58$ & $48.6 \pm 2.0$ \\
7 & $310.6 \pm 34$ & $822.4 \pm 64$ & $30.2 \pm 0.6$ \\
8 & $454.3 \pm 20$ & $775.3 \pm 52$ & $45.5 \pm 0.5$ \\
9 & $502.7 \pm 44$ & $820.6 \pm 58$ & $48.8 \pm 0.5$ \\
10 & $485.5 \pm 38$ & $832.5 \pm 55$ & $36.4 \pm 1.0$ \\
11 & $382.2 \pm 36$ & $750.4 \pm 63$ & $46.3 \pm 1.0$ \\
12 & $335.8 \pm 28$ & $796.5 \pm 68$ & $55.3 \pm 0.4$ \\
13 & $436.5 \pm 33$ & $836.7 \pm 63$ & $50.1 \pm 2.0$ \\
14 & $442.6 \pm 27$ & $828.6 \pm 53$ & $52.5 \pm 3.0$ \\
15 & $465.4 \pm 35$ & $840.8 \pm 68$ & $55.8 \pm 2.0$ \\
16 & $422.6 \pm 42$ & $862.4 \pm 80$ & $48.6 \pm 0.8$ \\
17 & $368.3 \pm 34$ & $874.8 \pm 75$ & $56.5 \pm 1.0$ \\
\hline
\end{tabular}

which is nearly same to the projected yield, and also specifies that the equation aligns well with the actual condition.

For all the levels of independent variables used in the trial, inulin particulate revealed sphericity, with a high deviation in diameter and with a petite trend to hitch together (agglomeration).

\section{Conclusion}

Inulin dry powder was produced via the spray drying process. The outcomes indicated that the product yield initially rises when independent variables were increased, and then afterwards declined. By employing Box-Behnken design for response surface analysis, the maximum product yield was $11.96 \%$, found within the optimum level of drying temperature $119.20^{\circ} \mathrm{C}$, the creeping speed of 21.64 $\mathrm{rpm}$, and the applied pressure of $0.03 \mathrm{MPa}$. The examination of the product morphology in an SEM revealed that on raising the temperature and decreasing the creep speed, powdered inulin sample offered spherical shape with smoother surfaces. Based on our research findings, we can accomplish that the spray drying technique may be utilized for the inulin production at commercial scale.

\section{Abbreviations \\ RSM: Response surface methodology; Rpm: Rotation per minute; ANOVA: Analysis of variance; DP: Degree of polymerization; $\mathrm{Ca}(\mathrm{OH})_{2}$ : Calcium hydroxide; SEM: Scanning electron microscope; FT-IR: Fourier transform- infrared; Diameter Avg: Average diameter; Diameter max: Maximum diameter; Diameter min: Minimum diameter}

\section{Acknowledgements}

The authors express special thanks to Suman Jain (Director, School of Studies in Pharmaceutical Sciences, Jiwaji University, Gwalior) and Mukul Tailang for his kind support (Department of Pharmaceutics, School of Studies in Pharmaceutical Sciences, Jiwaji University, Gwalior).

\section{Authors' contributions}

"WA" designed and optimized the study and developed the methodology. "WA" performed the experiments and collection and interpretation of data. "WA" wrote the manuscript. "NG" contributed to the manuscript revision and provided supervision. "WA" and "NG" read and approved the final manuscript. 


\section{Funding}

The University Grant Commission (UGC) is a funding agency which comes under the HRD ministry, Government of India. The main role of UGC in this research work was their financial support under the scheme of "Maulana Azad National Fellowship" (MANF) (201718-MANF-2017-18-MAD-85337).

\section{Availability of data and materials}

The datasets of research were collected from experiments and analysis of variables during current study. These datasets are available from the corresponding author on reasonable request.

\section{Ethics approval and consent to participate}

Not applicable.

\section{Consent for publication}

Not applicable.

\section{Competing interests}

The authors declare that they have no competing interests.

Received: 28 April 2020 Accepted: 31 August 2020

Published online: 09 October 2020

\section{References}

1. Mendes MF, Cataldo LF, da Silva CA, Nogueira Rl, Freitas SP (2005) Extraction of the inuline from chicory roots. 4th Mercosur Congress on Process Systems Engineering:1-8.

2. Petkova N, Ognyanov M, Denev P (2014) Isolation and charaterization of inulin obtained from taproots of common chicory (Cichorium intybus L.), University of Plovdiv "Paisii Hilendarski" Bulgaria. Scinetific papers 39(5):25-34

3. Akram W, Garud N, Joshi R (2019) Role of inulin as prebiotics on inflammatory bowel disease. Drug discoveries \& therapeutics 28;13(1):1-8.

4. Figueira GM, Park KJ, Brod FP, Honorio SL (2004) Evaluation of desorption isotherms, drying rates and inulin concentration of chicory roots (Cichorium intybus L.) with and without enzymatic inactivation. Food Eng 1;63(3):273-280

5. Chen GJ, Yang JK, Peng XB, He JR (2016) High-level secretory expression of Aspergillus exo-inulinase and its use in the preparation of fructose syrup from inulin. J Mol Catal B Enzym133:S543-S551.

6. Beccard S, Bernard J, Wouters R, Gehrich K, Zielbauer B, Mezger M, Vilgis TA (2019) Alteration of the structural properties of inulin gels. Food Hydrocoll 1; 89:302-310.

7. Liu J, Luo D, Li X, Xu B, Zhang X, Liu J (2016) Effects of inulin on the structure and emulsifying properties of protein components in dough. Food Chem 1;210:235-241

8. Toneli J, Park K, Negreiros A, Murr F (2010) Spray-drying process optimization of chicory root inulin. Dry Technol 8;28(3):369-379.

9. Ahmad S, Nema PK, Bashir K (2018) Effect of different drying techniques on physicochemical, thermal, and functional properties of seera. Dry Technol 18;36(11):1284-1291.

10. Hang H, Li Y, Zhao M, Jiang B, Miao M, Mu W, Zhang T (2013) Dry powder preparation of inulin fructotransferase from Arthrobacter aurescens SK 8.001 fermented liquor. Carbohydr Polym 20;95(2):654-656.

11. Hibler S, Gieseler H (2012) Heat transfer characteristics of current primary packaging systems for pharmaceutical freeze-drying. J Pharm Sci 1;101(11): 4025-4031.

12. Litvin S, Mannheim CH, Miltz J (1998) Dehydration of carrots by a combination of freeze drying, microwave heating and air or vacuum drying. J Food Eng. 1;36(1):103-111.

13. Moayyedi M, Eskandari MH, Rad AH, Ziaee E, Khodaparast MH, Golmakani MT (2018) Effect of drying methods (electrospraying, freeze drying and spray drying) on survival and viability of microencapsulated Lactobacillus rhamnosus ATCC 7469. J Funct Foods 1;40:391-399.

14. Walz M, Hirth T, Weber A (2018) Investigation of chemically modified inulin as encapsulation material for pharmaceutical substances by spray-drying. Colloids Surf A Phys Eng Asp 5;536:47-52.

15. Liu S, Shi $X, X u L$, Yi Y (2016) Optimization of pectin extraction and antioxidant activities from Jerusalem artichoke. J Oceanol Limnol 1; 34(2):372-381.
16. Sharma P, Tailang M (2020) Design, optimization, and evaluation of hydrogel of primaquine loaded nanoemulsion for malaria therapy. Futur J Pharm Sci 6:26

17. Grube M, Bekers M, Upite D, Kaminska E (2002) Infrared spectra of some fructans. J Spectros 16(3-4):289-296

18. Olennikov DN, Tankhaeva LM, Rokhin AV (2011) Glucofructans from Saussurea lappa roots. Chem Nat Compd 1;47(3):339-342.

19. Praznik W, Beck RHF (1985) Application of gel permeation chromatographic systems to the determination of the molecular weight of inulin. J Chromatogr A 348:187-197

20. Franck A (2002) Technological functionality of inulin and oligofructose. Br J Nutr 87(S2):S287-S291

\section{Publisher's Note}

Springer Nature remains neutral with regard to jurisdictional claims in published maps and institutional affiliations.

\section{Submit your manuscript to a SpringerOpen ${ }^{\circ}$ journal and benefit from:}

- Convenient online submission

- Rigorous peer review

- Open access: articles freely available online

High visibility within the field

- Retaining the copyright to your article

Submit your next manuscript at $\boldsymbol{\nabla}$ springeropen.com 